\title{
Maksillada fibröz displazi: İki olgu sunumu*
}

\author{
Ahmet Altan', ỉbrahim Damlar², Soydan Kılıç², Berk Turgay², Zeynel Abidin Taş ${ }^{3}$
}

Selcuk Dental Journal, 2015; 2: 86-90

Başvuru Tarihi: 12 Haziran 2015 Yayına Kabul Tarihi: 02 Ağustos 2015

\section{Fibrous dysplasia in the maxilla: Report of two cases}

Fibrous dysplasia is a developmental, slow growing, benign fibrous-osseous lesion of the bone and is generally seen in children and adolescents. Fibrous dysplasia has two clinical forms; monostotic and polyostotic. Increases in bone formation within the lesion create a radiographic appearance that is referred to as 'ground glass' or 'orange peel'. In this report, two fibrous dysplasia, whose diagnosis are made with clinical, histopathological and radiographic information, are presented.A 19-year-old male patient reported to our department with a chief complaint of swelling in the upper right region since 3 months. The swelling was asymptomatic. Oral examination revealed the presence an expansion in the vestibule of the alveolar ridge of upper jaw. Under local anesthesia the lesion's size was reduced with the contour correction for functional and esthetic problems.56-year-old female patient admitted our clinic with a swelling in right maxilla. Intraoral examination revealed vestibular and palatal bone expansion in the right maxilla. The histological findings led to the definite diagnosis fibrous dysplasia. The large and asymptomatic lesion is being followed-up with monthly visits.Fibrous displasia in jaws is rare and can be difficult to differentiate from other benign and malignant bone disorders. Malignant transformation is extremely rare and appears almost exclusively in polyostotic cases. Therefore the following period is important.

\section{KEY WORDS}

\section{Fibrous dysplasia, maxilla, monostotic}

Fibröz displazi (FD), normal kemiğin yapısal olarak daha zayıf fibröz ve osseöz doku ile yer değiştirmesi sonucu oluşan, lokalize, gelişimsel, iyi huylu bir kemik hastalığıdır (Akçiçek ve ark 2007, Çakur ve ark 2014). Normal kemiğin yerini alan fibröz bağ dokusunun içinde kemik trabekülleri mevcuttur (Selçuk ve ark. 2013). FD klinik olarak tek bir kemiği tutan monostotik FD ve çok sayıda kemiği etkileyen poliostotik FD olmak üzere ikiye ayrilır (Sontakke ve ark 2011). Poliostotik FD; Jaffe tipi ve ciddi seyreden McCune Albright Sendromu olarak iki grupta incelenmektedir. Jaffe tipinde çok sayıda kemikte FD, 'sütlü kahve lekeleri' adı verilen deri pigmentasyonları görülmektedir. McCune Albright Sendromu ise deri pigmentasyonları ile beraber hemen hemen tüm kemikleri tutan ciddi bir endokrin bozuklukluğudur (Sontakke ve ark. 2011, Ünlü 2014). Bazı araştırmacılar iki veya daha fazla fasiyal ve kraniyal kemiği etkileyen FD'yi kraniyofasiyal FD olarak sınıflandırmıştır (Cheng ve ark 2012, Cholakova ve ark 2010, Lustig ve ark 2001).

Fibröz displazi kemik tümörlerinin \% 3'ünü, iyi huylu kemik tümörlerinin ise \% 7'sini oluşturmaktadır (Bequignon ve ark 2013). Kafa kemikleri en fazla etkilenen kemiklerdir. Bu patolojik durum maksillada mandibulaya göre daha çok görülür ve maksillada sıklıkla unilateral, posterior bölgede tutulum gösterir (Menon ve ark 2013).

Fibröz displazide konvansiyonel radyograflar, bilgisayarlı tomografi, sintigrafi ve histopatolojik yöntemler yardımıyla inceleme yapılabilir (Sontakke ve ark 2011). FD'nin radyografik özellikleri lezyonun maturasyon derecesine göre değişiklik göstermektedir. Radyografik görüntü tipik olarak 'buzlu cam' ya da 'portakal kabuğu' şeklinde tarif edilir (Mohammadi-Araghi ve Haery 1993, Akçiçek ve ark 2007).

\footnotetext{
* Türk Oral ve Maksillofasiyal Cerrahi Derneği, 22. Uluslararası Bilimsel Kongresi, 19-23 Mayıs 2015, Muğla/Türkiye'de poster bildirisi olarak sunulmuştur.

${ }^{1}$ Gaziosmanpaşa Üniversitesi Diş Hekimliği Fakültesi Ağız Diş ve Çene Cerrahisi Anabilim Dalı

2 Mustafa Kemal Üniversitesi Diş Hekimliği Fakültesi Ağız Diş ve Çene Cerrahisi Anabilim Dalı

${ }^{3}$ Mustafa Kemal Üniversitesi Tıp Fakültesi Tıbbi Patoloji Anabilim Dalı
} 
Fibröz displazi lezyonları ağrısız ve yavaş büyüyen şişliklerdir. Lezyon büyük boyutlara ulaşarak fonksiyon bozukluğuna ve dişlerin yer değiştirmesiyle oklüzyon bozukluklarına neden olabilir (Pruksakorn ve ark 2010). Fibröz displazinin lokalizasyonuna ve tipine bağlı olarak görme değişiklikleri, işitme kaybı, nazal obstrüksiyon, parestezi ve ağrı gibi semptomlar görülebilir (Lee ve ark 2012).

Fibröz displazi; müdahale edilmeden takip edilebileceği gibi medikal olarak, konservatif cerrahiyle, radikal eksizyon veya rekonstrüksiyon ile tedavi edilebilir (Menon ve ark 2013). Cerrahi tedavinin amacl; hastaları patolojik fraktürlerden korumak, ağrıyı ortadan kaldırmak ve kemik deformitelerini azaltmaktır.

$\mathrm{Bu}$ makalede sadece maksillayı tutan, klinik, radyografik ve histopatolojik değerlendirmeler sonrası fibröz displazi tanısı konulan iki olgunun sunumu amaçlanmıştır.

\section{OLGU SUNUMU}

\section{OLGU 1}

19 yaşında erkek hasta, Mustafa Kemal Üniversitesi Diş Hekimliği Fakültesi Ağız Diş ve Çene Cerrahisi kliniğine üst çenede şişlik şikayetiyle başvurdu. Alınan anamnezde şişliğin yaklaşık altı ay önce oluşmaya başladığı ve büyüklüğünün zamanla arttığı öğrenildi. Herhangi bir sistemik rahatsızlığı olmayan hastanın ağız içi muayenesinde, sağ maksilla anterior bölgede vestibüle ekspansiyon gösteren ağrısız, sert, kemik benzeri bir çıkıntı gözlendi (Resim-1). Alınan panoramik radyografta; kemikte sağ maksiller santral ve birinci premolar dişler arasında kalan bölgede, dişlerin kökleri hizasında FD'nin karakteristik bulgusu olan 'buzlu cam' görüntüsü saptandı (Resim-2). Detaylı inceleme yapabilmek amacıyla alınan bilgisayarlı tomografide diğer kemiklerde tutulum gözlenmedi (Resim-3). Radyololojiyle yapılan konsültasyonda; küçük boyutlardaki lezyonda kemik sintigrafisine intiyaç duyulmadı. Klinik ve radyografik muayeneler sonucunda monostotik FD ön tanısı konulan lezyondan biyopsi alınmasına karar verildi. Lokal anestezi altında lezyonun vestibüle doğru ekspansiyon yapan kısmı çıkarıldı (Resim-4a). Kontur düzeltmesi yapılarak estetik problem ortadan kaldırıldı. Histopatolojik incelemede kesitlerde sellüler fibroblastik stroma içerisinde lameller kemik dokusu izlendi (Resim-4b). Elde edilen sonuç ön tanıyla uyumluydu. Takibi devam eden hastanın bir yıldır yapılan kontrollerinde herhangi bir kemik büyümesi ya da problemle karşılaşılmadı.

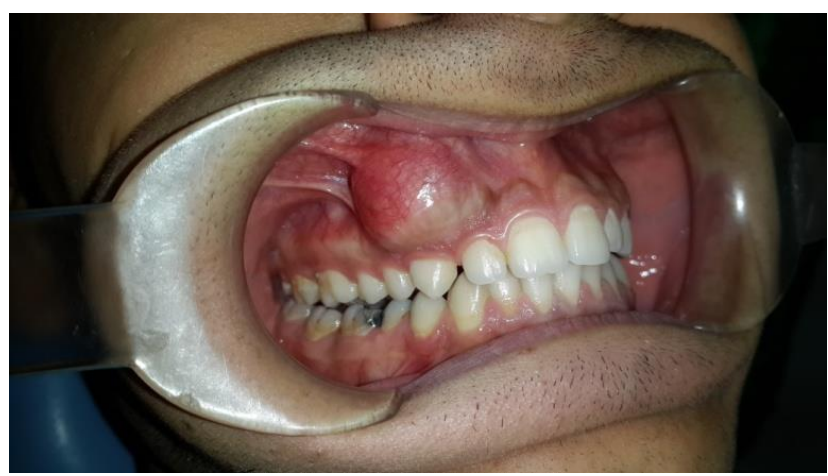

Resim 1.

Maksilla anterior bölgede yer alan lezyonun ağız içi görünümü

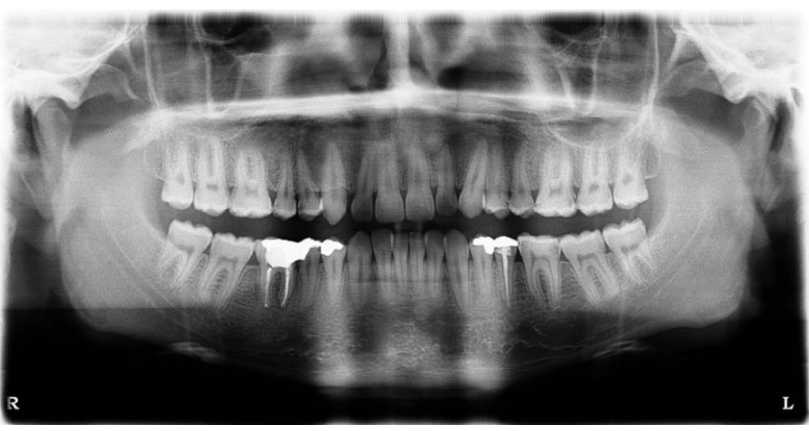

Resim 2.

Sağ üst çenedeki lezyonun panoramik radyografideki görüntüsiu
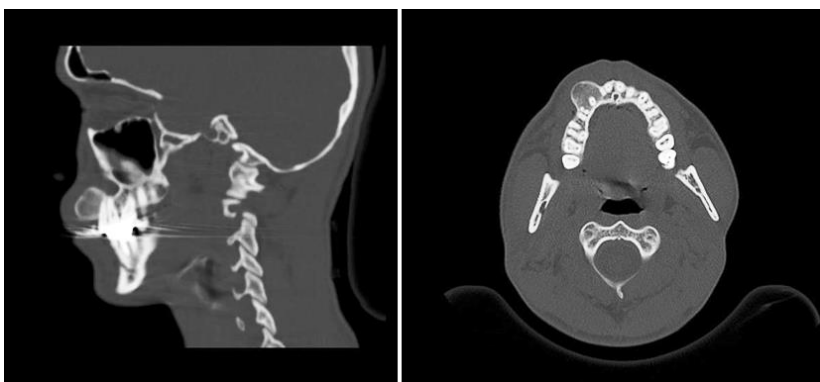

Resim 3.

Maksilla anterior bölgede lokalize lezyonun BT aksiyel ve sagittal kesitte görüntüsü
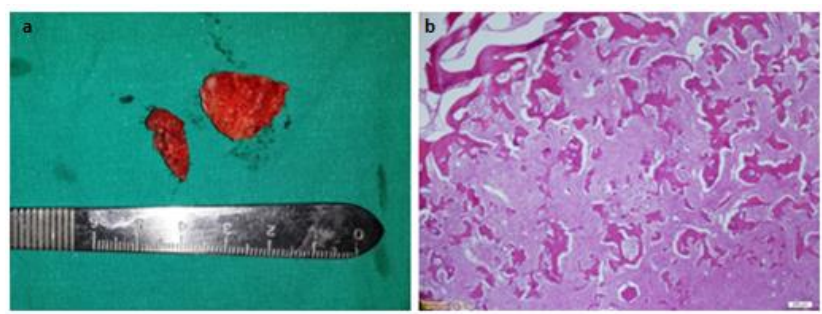

Resim 4.

a) Cerrahi operasyonla çıkarılan kitle

b) Sellüler fibroblastik stroma içerisinde lameller kemik dokusunu gösteren mikroskobik kesit (Hematoksilen-Eozinx40) 


\section{OLGU 2}

56 yaşında kadın hasta sağ üst çenede şişlik şikayetiyle Mustafa Kemal Üniversitesi Diş Hekimliği Fakültesi Ağız Diş ve Çene Cerrahisi kliniğine başvurdu. Anamnezde şişliğin uzun zamandır var olduğu, yavaş bir şekilde büyüdüğü öğrenildi. Şişliğin olduğu bölgede ikinci molar dişin çekildiği ve sabit restorasyon yapıldığı görüldü. Herhangi bir sistemik hastalığı olmayan hastanın klinik muayenesinde; sağ maksilla anterior bölgeden tüber maksillaya kadar uzanan, vestibül ve palatinale ekspansiyon gösteren; kemik sertliğinde, ağrısız bir şişlik saptandı (Resim-5).
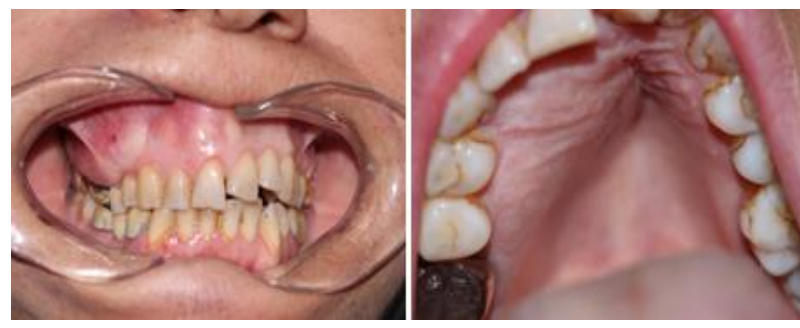

Resim 5.

Maksillada palatinal ve vestibüle ekspansiyon gösteren lezyonun

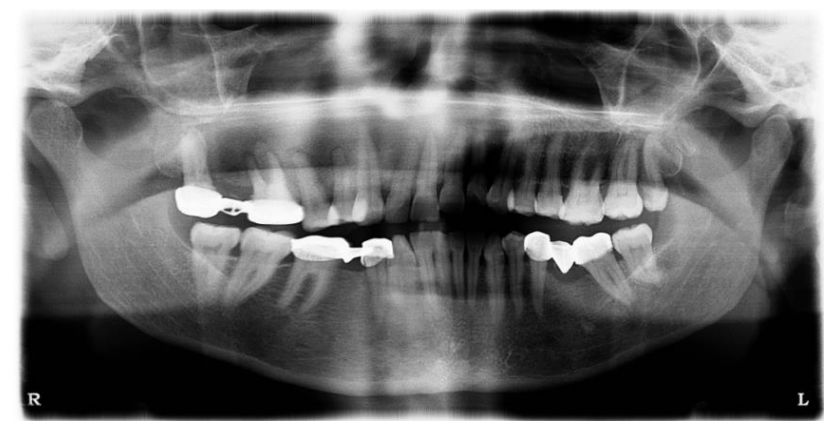

Resim 6.

Sağ üst çeneyi tutan lezyonun panoramik radyografideki buzlu cam görüntüsü

\section{TARTIŞMA}

Fibröz displazinin tüm formları kadın ve erkeklerde cinsiyet ayrımı yapmaksızın eşit bir şekilde görülür (Menon ve ark 2013, Posnick 1998). Ancak Kruse ve arkadaşları (Kruse ve ark 2009) hastalığın kadınlarda daha sık görüldüğünü rapor etmiştir. Sıklıkla yaşamın ilk üç dekatında kendini gösteren hastalıkta iskeletsel gelişimin tamamlanmasıyla lezyonların stabilize olacağı düşünülür (Rahman ve ark 2009). Sunduğumuz vakalarda erkek hastanın yaşı 19 olup
Panoramik radyografide yapılan incelemede sağ maksillanın tamamında FD'nin karakteristiğiyle karakteristiğiyle uyumlu 'buzlu cam' görüntüsü saptandı (Resim-6). Alınan bilgisayarlı tomografide lezyonun sınırlarının palatinal orta hatta kadar uzandığı ve lezyonun sağ maksillanın tamamına yayıldığı gözlendi (Resim-7). Yapılan insizyonel biyopsinin histopatolojik incelemesinde gevşek fibröz stroma içinde düzensiz şekilli kompakt kemik lamelleri izlendi ve fibröz displazi tanısı konuldu (Resim-8). İleri yaştaki hastada, büyük boyutlara ulaşmış ve asemptomatik olan lezyona cerrahi bir müdahale düşünülmedi. Altı aydır takibi yapılan hastanın, aylık rutin kontrolleri devam etmektedir.
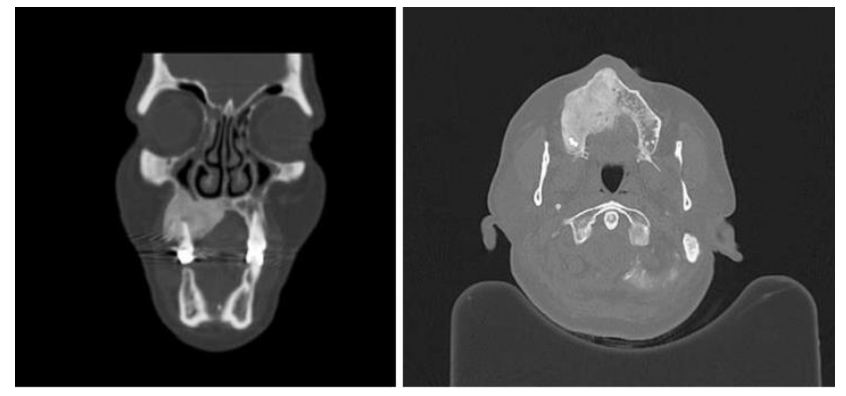

Resim 7

Palatinal orta hatta kadar uzanan lezyonun BT koronal ve aksiyel kesitte görüntüsü

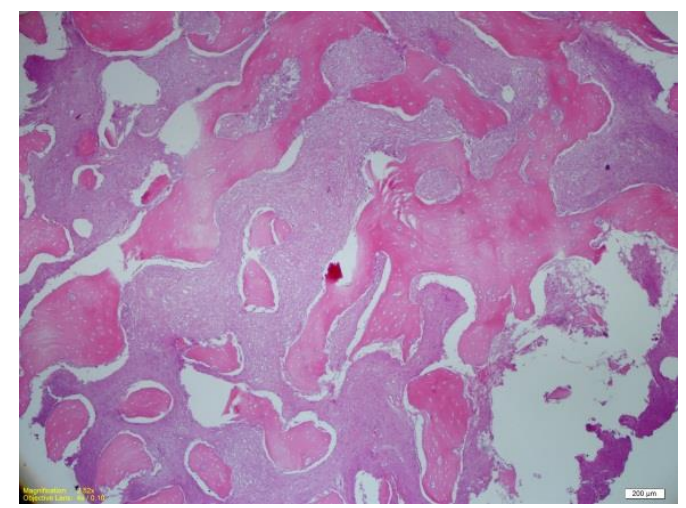

Resim 8.

Lezyonun mikroskobik görüntüsünde gevşek fibröz stroma içinde düzensiz şekilli kompakt kemik lamelleri görülmekte (Hematoksilen-Eozinx40)

literatür bilgileriyle uyumluyken; iskeletsel gelişimini tamamlamış kadın hastanın yaşı literatür bilgilerine göre daha ileridir.

Kemik tümörlerinin \% 3'ünü oluşturan FD'nin iyi huylu kemik tümörler içersisindeki görülme sıklığı \% 7'dir (Bequignon ve ark 2013). Lustig ve arkadaşları (Lustig ve ark 2001) kafatası kemiklerinde sıklıkla ethmoid kemiğin, daha sonra sırası ile sfenoid, frontal, maksilla, temporal, 
parietal ve oksipital kemiklerin tutulum gösterdiğini rapor etmişlerdir. Maksillada genellikle unilateral görülen lezyonlar, posterior bölgede daha çok yerleşim gösterirler (Menon ve ark 2013). Sunduğumuz olgularda maksillada tutulum gösteren FD, bir vakada posterior diğerinde anterior bölgede lokalizeydi.

Poliostotik FD tanısı genelde klinik muayene ve radyografik bulgularla konulurken, monostotik FD tanısında kemik biyopsisi gerekir (Menon ve ark 2013). Fibröz displazinin ayırıcı tanısı; ossifiye fibrom, Paget hastalığı, anevrizmal kemik kistleri, dev hücreli tümör, dev hücreli reperatif granülom ve Brown tümörü ile yapılmalıdır (Lustig et al 2001). Konvansiyonel radyograflar, bilgisayarlı tomografi, sintigrafi ve histopatolojik yöntemler tanı koymaya yardımcı yöntemlerdir (Sontakke ve ark 2011). Bilgisayarlı tomografi lezyonun kesin sınırlarının belirlenmesinde ayrı bir öneme sahiptir (Mohammadi-Araghi ve Haery 1993). Lezyonun maturasyon derecesine göre değişiklik gösteren radyografik görüntü tipik olarak 'buzlu cam' ya da 'portakal kabuğu' şeklinde tarif edilir (MohammadiAraghi ve Haery 1993, Akçiçek ve ark. 2007). Makalemizde sunulan iki olguda da kesin tanının konulmasında klinik muayene ve FD'nin tipik buzlu cam görüntüsü yol gösterici olmuştur. Bilgisayarlı tomografiyle sınırları tespit edilen lezyonların biyopsi sonrası yapılan histopatolojik incelemeleriyle monostotik FD tanısı doğrulanmıştır.

Ağrısız ve yavaş büyüyen fibröz displazi lezyonlarının maksilla ve mandibuladaki tutulumlarında dişler gömülü kalabilir; dişlerin yer değiştirmesiyle maloklüzyon meydana gelebilir (Akçiçek ve ark 2007, Pruksakorn ve ark 2010). Mandibuladaki FD lezyonları mandibular kanalın yer değiştirmesine neden olabilirken; maksilla yerleşimli lezyonlar maksillar sinüsü içine alıp; göz tabanını etkileyebilir (Selçuk ve ark. 2013, Mohammadi-Araghi ve Haery 1993). Görme değişiklikleri, nasal obstrüksiyon, işitme kaybı, parestezi ve ağrı gibi semptomlara neden olduğu da bildirilmiştir (Lee ve ark 2012). Sunduğumuz vakalarda lezyonlar maksilla yerleşimli olup ağrısız şişlikler mevcuttu.

Fibröz displazinin tedavi seçenekleri; gözlem, medikal tedavi, konservatif cerrahi, radikal eksizyon ve rekonstrüksiyon şeklinde sıralanabilir (Menon ve ark 2013). Hasta için kozmetik problem oluşturmayan küçük, asemptomatik lezyonların tedavisinde takip en iyi tedavi seçeneklerinden biridir (Menon ve ark. 2013). Medikal tedavide bifosfonat (Kos ve ark 2004) ve kalsitonin (Yasuoka ve ark 2003) gibi ilaçlar önerilmiştir ancak bu yöntem FD lezyonlarının tedavisinde öncü bir rol oynamamaktadır. Kraniyofasiyal bölgede görülen FD'de sabit bir tedavi protokolü olmamasına rağmen; fonksiyonun ve yüz estetiğinin sağlanmasında cerrahi yöntemler önemli bir yere sahiptir (Menon ve ark 2013). Sunulan olguların ilkinde anterior bölgede konumlanan, hasta için estetik problem oluşturan lezyonda kontur düzeltme işlemi yapıldı. İkinci olguda ileri yaştaki hastada, posteriorda konumlanan, maloklüzyon, fonksiyon kaybı ya da önemli anatomik oluşumlara bir etkisi olmayan lezyonun takibi uygun görüldü.

Çene yüz bölgesinde görülen FD'de hastalığın seyri genellikle iyi olmasına rağmen, spontan malign transformasyon görülen vakalar mevcuttur (Sadeghi ve Hosseini 2011). Radyasyonun malign değişikliklere yol açacağı göz önünde bulundurulup, lezyonların tedavisinde radyoterapiden kaçınılmalıdır (Yabut ve ark 1988, Akçiçek ve ark 2007).

Sonuç olarak; sıklıkla genç yaşlarda görülen fibröz displazinin ileri yaşlarda da ortaya çıkabileceği akılda tutulmalıdır. Lezyonun malign olmadığı konusunda hasta rahatlatılmalıdır. Nüks ve düşükte olsa malign transformasyon riskine karşlık hasta kontrolleri inmal edilmemelidir.

\section{Maksillada fibröz displazi: Íki olgu sunumu}

Fibröz displazi genellikle çocuklarda ve ergenlerde görülen; kemiğin gelişimsel, yavaş büyüyen, fibroosseöz benign bir lezyonudur. Monostotik ve poliostotik olmak üzere iki klinik formu vardır. Lezyon içindeki kemik oluşumunda artışla birlikte 'buzlu cam' veya 'portakal kabuğu' olarak adlandırılan radyografik görüntü oluşur. Bu makalede klinik, radyografik ve histopatolojik bulgularla tanı konulmuş iki fibröz displazi olgusu sunulmuştur.19 yaşında erkek hasta, 3 aydan beri var olan sağ üst bölgede şişlik şikayetiyle kliniğimize başvurdu. Klinik muayene sonucunda üst çene anterior bölgede vestübüle ekspansiyon gösteren asemptomatik bir lezyon tespit edildi. Lokal anestezi altında kontur düzeltmesi yapılarak fonksiyonel ve estetik sorunlar ortadan kaldırıldı.56 yaşındaki bayan hasta sağ maksillada şişlik şikayetiyle kliniğimize başvurdu. Ağız içi muayenede sağ maksillada vestibüle ve palatinale ekspansiyon gösteren bir şişlik görüldü. İnsizyonel biyopsi sonucunda fibröz displazi tanısı konuldu. İleri yaştaki hastada, büyük boyutlardaki asemptomatik lezyonun aylık kontrollerle takip edilmesine karar verildi.Çene kemiklerinde fibröz displazi nadir görülen bir durumdur. Diğer benign ve malign kemik bozukluklardan ayırt edilmesi zor olabilir. Malign transformasyon son derece nadirdir ve daha çok poliostotik tipte görülür. Bu nedenle takibi önemlidir.

\section{ANAHTAR KELIMELER}

Fibröz displazi, maksilla, monostotik 


\section{KAYNAKLAR}

Akçiçek GT, Akkaya N, Avcu N, Alan A, Dural S, 2007. Monostotik Fibröz Displazi. Hacettepe Dişhekimliği Fakültesi Dergisi, 31, 41-46.

Bequignon E, Cardinne C, Lachiver X, Wagner I, Chabolle F, Baujat B, 2013. Craniofacial fibrous dysplasia surgery: a functional approach. Eur Ann Otorhinolaryngol Head Neck Dis, 130, 215-220.

Cheng J, Wang Y, Yu H, Wang D, Ye J, Jiang $\mathrm{H}$, Wu $Y$, Shen G, 2012. An epidemiological and clinical analysis of craniomaxillofacial fibrous dysplasia in a Chinese population. Orphanet J Rare Dis, 7, 80.

Cholakova R, Kanasirska P, Kanasirski N, Chenchev I, Dinkova A, 2010. Fibrous dysplasia in the maxillomandibular region-case report. Journal of IMAB, 16, 10-13.

Çakur B, Durna D, Bilge OM, Yıldırım E, 2014. Fibröz Displazi: Bir Olgu Sunumu. Atatürk Üniv. Diş Hek. Fak. Derg, Suppl 8, 1-3.

Kos M, Luczak K, Godzinski J, Klempous J, 2004. Treatment of monostotic fibrous dysplasia with pamidronate. J Craniomaxillofac Surg, 32, 10-15.

Kruse A, Pieles U, Riener MO, Zunker C, Bredell MG, Gratz KW, 2009. Craniomaxillofacial fibrous dysplasia: a 10-year database 1996-2006. Br J Oral Maxillofac Surg, 47, 302-305.

Lee JS, FitzGibbon EJ, Chen YR, Kim HJ, Lustig LR, Akintoye SO, Collins MT, Kaban LB, 2012. Clinical guidelines for the management of craniofacial fibrous dysplasia. Orphanet J Rare Dis, 7 Suppl 1, 2.

Lustig LR, Holliday MJ, McCarthy EF, Nager GT, 2001. Fibrous dysplasia involving the skull base and temporal bone. Arch Otolaryngol Head Neck Surg, 127, 1239-1247.

Menon S, Venkatswamy S, Ramu V, Banu K, Ehtaih S, Kashyap VM, 2013. Craniofacial fibrous dysplasia: Surgery and literature review. Ann Maxillofac Surg, 3, 66-71.

Mohammadi-Araghi H, Haery C, 1993. Fibro-osseous lesions of craniofacial bones. The role of imaging. Radiol Clin North Am, 31, 121-134.

Posnick JC, 1998. Fibrous dysplasia of the craniomaxillofacial region: current clinical perspectives. Br J Oral Maxillofac Surg, 36, 264-273.

Pruksakorn P, Shuangshoti S, Siwanuwatn R, Lerdlum S, Sunthornyothin S, Snabboon T, 2010. Craniofacial fibrous dysplasia. Intern Med, 49, 24950.
Rahman AM, Madge SN, Billing $\mathrm{K}$, Anderson PJ, Leibovitch I, Selva D, David D, 2009. Craniofacial fibrous dysplasia: clinical characteristics and longterm outcomes. Eye (Lond), 23, 2175-2181.

Sadeghi SM, Hosseini SN, 2011. Spontaneous conversion of fibrous dysplasia into osteosarcoma. J Craniofac Surg, 22, 959-961.

Selçuk Ü, Muğlalı M, Çelenk P, Canger M, Günhan Ö, 2013. Monostatik fibröz displazi: Olgu sunumu. Journal of Experimental and Clinical Medicine, 30, 91-93.

Sontakke SA, Karjodkar FR, Umarji HR, 2011. Computed tomographic features of fibrous dysplasia of maxillofacial region. Imaging Sci Dent, 41, 23-28.

Ünlü E, 2014. Maksiller Fibröz Displazi: Vaka Sunumu. Kocatepe Tıp Dergisi, 15, 58-61.

Yabut SM, Kenan S, Sissons HA, Lewis MM, 1988. Malignant transformation of fibrous dysplasia. A case report and review of the literature. Clin Orthop Relat Res, 281-9.

Yasuoka T, Takagi N, Hatakeyama D, Yokoyama K, 2003. Fibrous dysplasia in the maxilla: possible mechanism of bone remodeling by calcitonin treatment. Oral Oncol, 39, 301-305.

\section{Ahmet ALTAN}

Gaziosmanpaşa Üniversitesi

Diş Hekimliği Fakültesi

Ağız Diş ve Çene Cerrahisi AD

Ali Şevki EREK Yerleşkesi

Tokat/TÜRKIYE

Tel: +90 (505) 7013189

E-mail: dt.ahmetaltan@gmail.com 